\title{
The Regulation of Glucose-Induced Insulin Secretion by Pre-Stimulus Glucose Level and Tolbutamide in Normal Man
}

\author{
M. A. Pfeifer, R. J. Graf, J. B. Halter and D. Porte, Jr. \\ Department of Medicine, Division of Endocrinology and Metabolism, University of Washington School of Medicine \\ and the Geriatric Research, Education and Clinical Center, Veterans Administration Medical Center, Seattle, Washington, USA
}

Summary. The relationship between the pre-stimulus glucose level and immunoreactive insulin responses to a glucose challenge (20-g IV) was studied in normal subjects. When the steady-state pre-stimulus glucose concentration was lowered by a $0.33 \mathrm{mU}$. $\mathrm{kg}^{-1} \cdot \min ^{-1}$ insulin infusion or raised by a $900 \mathrm{mg} /$ min glucose infusion, no effect on first phase insulin secretion (mean $\Delta 3-5 \mathrm{~min}$ insulin level) was observed. In contrast, the second phase response (10-60 min insulin area after glucose pulse) to intravenous glucose fell during insulin infusion and increased during the glucose infusion. Overall, a linear relationship was found between the change of pre-stimulus glucose level from the control to that during the insulin or glucose infusion and the change in second phase response $(r=0.65, n=14$, $p<0.02)$. The effect of tolbutamide infusion $\left(7 \mathrm{mg} \cdot \mathrm{m}^{-2} \cdot \mathrm{min}^{-1}\right)$ when compared with saline control was to increase both first phase $(+54 \pm 13 \mathrm{mU} / \mathrm{l}$, $n=8, p<0.001$, mean $\pm \mathrm{SEM})$ and second phase $\left(+972 \pm 256 \mathrm{mU} \cdot \mathrm{min}^{-1} \cdot \mathrm{1}^{-1}, p<0.01\right)$ insulin secretion. It is concluded that the first phase response to a glucose pulse is independent of the steady-state pre-stimulus glucose concentration and is directly enhanced by tolbutamide; in contrast, second phase is related to both the steady-state pre-stimulus glucose level and tolbutamide. These findings suggest that changes in basal or pre-stimulus plasma glucose during therapy with sulphonylurea drugs may be expected to influence the second phase insulin responses to glucose challenge.

Key words: Intravenous glucose tolerance test, first phase insulin secretion, second phase insulin secretion, glucose potentiation, tolbutamide
The pre-stimulus glucose level is an important determinant of insulin responses to non-glucose stimuli in man $[1,2]$; that is, the lower the pre-stimulus glucose level the smaller the insulin response and the higher the level, the greater the response. The present study was designed to determine the relationship between insulin responses to a glucose stimulus and the prestimulus glucose level, and to determine whether such a relationship would be important to an analysis of the effect of tolbutamide on glucose-induced insulin release.

\section{Subjects and Methods}

\section{Subjects}

Fifteen lean male volunteers (percentage ideal body weight $=109$ \pm 4 ; mean \pm SEM) were studied. Their average age was 31 years (range 21-47 years). None of the subjects was using any medications at the time of study, and none had a history of cardiovascular disease. All subjects had fasting plasma glucose levels of less than $5.83 \mathrm{mmol} / \mathrm{l}(5.38 \pm 0.06 \mathrm{mmol} / \mathrm{l})$ and had no family history of diabetes mellitus. Studies were performed after an overnight fast, and no cigarette smoking was allowed on the days of the studies. Aspirin and aspirin-containing products were not allowed for a period of at least one week before the studies. All subjects were eating ad lib diets prior to the studies. Informed consent was obtained from all subjects.

\section{Study Protocols}

All studies were performed in a metabolic ward. A 19-gauge butterfly needle was introduced into each antecubital vein and was kept patent by a slow infusion of $0.154 \mathrm{~mol} / 1$ sodium chloride. Venous samples were obtained from one IV line for laboratory analyses. The other IV line was used for administration of the drugs during the study. Five-ml samples for measurement of plasma immunoreactive insulin (IRI) and glucose were anticoagulated with EDTA, kept on ice until the plasma was separated by centrifugation, and subsequently frozen for analysis at a later time. Samples of blood $(2.5 \mathrm{ml})$ for measurements of plasma nor- 


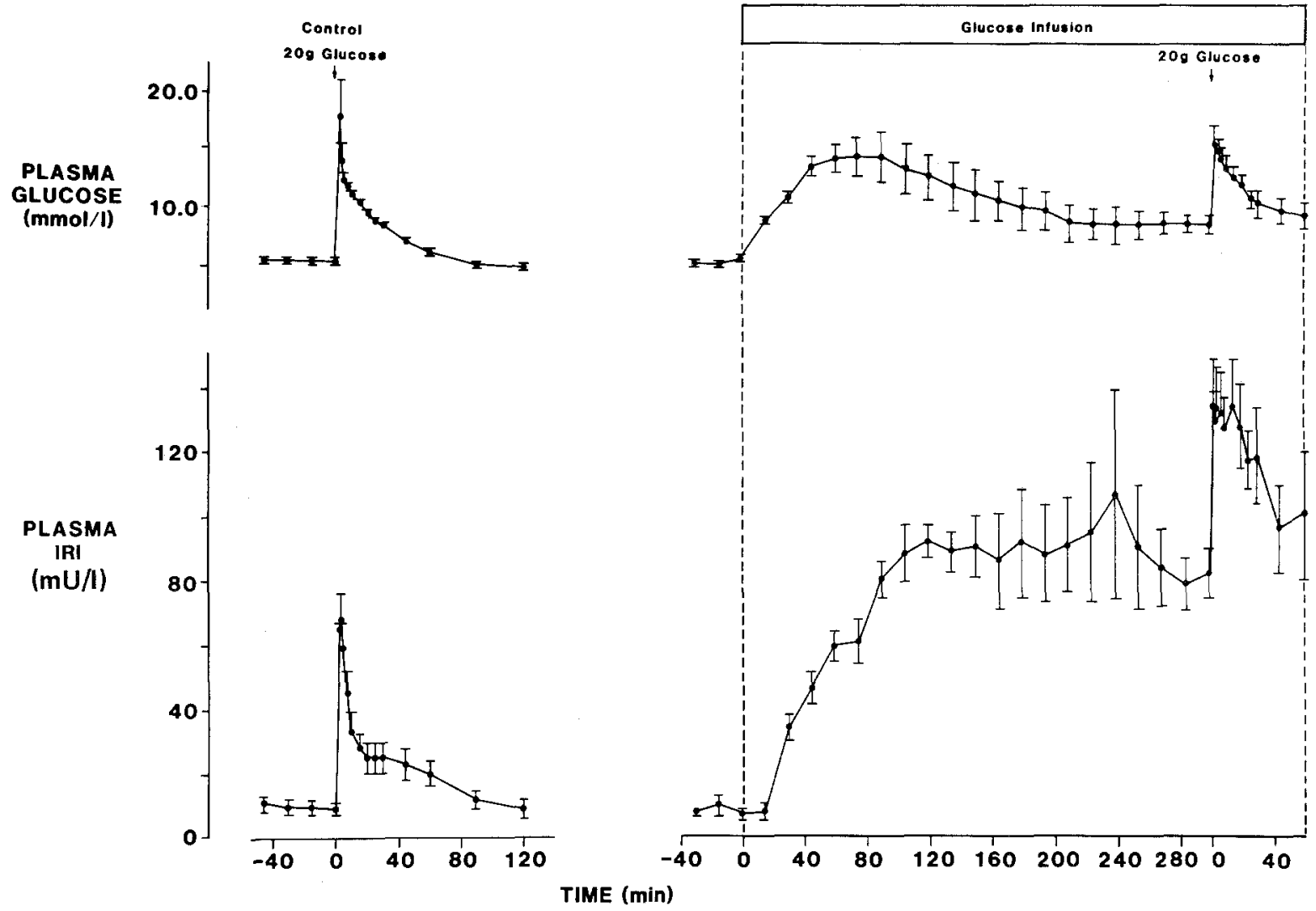

Fig. 1. Effect of an increased pre-stimulus plasma glucose concentration on insulin release to a $20 \mathrm{~g}$ IV glucose challenge. Seven normal subjects had the pre-stimulus glucose level elevated and maintained at a new steady-state level by a $5 \mathrm{~h}$ infusion of glucose ( $900 \mathrm{mg} / \mathrm{min}$ ). The left panel demonstrates a control day for the same subjects. All values are mean $\pm S E M$ of seven subjects

adrenaline and adrenaline were collected in pre-chilled tubes containing ethyleneglycoltetraacetic acid (EGTA) for anticoagulation and gluthathione to prevent oxidation. Final blood concentration of EGTA and gluthathione was 4.7 and $3.9 \mathrm{mmol} / \mathrm{l}$, respectively. These samples were kept on ice until the plasma was separated by double centrifugation (within $30 \mathrm{~min}$ ), and subsequently frozen for analysis at a later time.

In all studies, a 20 -g glucose pulse was given rapidly (less than $10 \mathrm{~s}$ ) intravenously. This dose has been previously determined to be a near maximal stimulus for first phase insulin secretion in normal man [3]. The first phase insulin response to glucose was calculated as the mean increase above the pre-stimulus plasma insulin level at 3, 4, and 5 min after the glucose pulse. The second phase insulin response to glucose was calculated as the area above the pre-stimulus baseline level for the tenth through sixtieth minute period following the glucose pulse. The glucose disappearance rate $\left(\mathrm{K}_{\mathrm{G}}\right)$ after the glucose pulse is the negative slope of the linear relationship between the natural log of glucose level versus time during the tenth through thirtieth min period following the pulse.

Samples for measurement of plasma catecholamine levels were obtained at 40 and $45 \mathrm{~min}$ after placing of the IV lines in the saline control, tolbutamide, and insulin infusion studies. The mean of these two measurements was used as the baseline level and compared with the mean of two samples obtained $5 \mathrm{~min}$ before and immediately preceding the administration of each glucose pulse. Catecholamine samples were also obtained every $30 \mathrm{~min}$ during the insulin infusion study (described below) to assure that no hypoglycaemia-induced adrenergic response occurred during this period. Serum tolbutamide concentrations were determined after one hour of the tolbutamide infusion (immediately preceding a glucose pulse).

In seven subjects, a 30 -min basal period was followed by a $6-h$, $900 \mathrm{mg} / \mathrm{min}$ glucose infusion. This $6-\mathrm{h}$ infusion was to allow a new steady-state for insulin and glucose to be achieved for at least $90 \mathrm{~min}$ before the glucose pulse. The glucose pulse was administered at the initiation of the sixth hour of the concomitant glucose infusion. These results were compared with studies performed on a separate day in the same subjects when the glucose pulse was administered directly after a 30 -min basal period.

In seven subjects, a $45-\mathrm{min}$ basal period was followed by a $1 \mathrm{~h}$ infusion $\left(0.33 \mathrm{mU} \cdot \mathrm{kg}^{-1} \cdot \mathrm{min}^{-1}\right)$ of regular pork-beef insulin (Lilly, Indianapolis, Indiana, USA). Protein was not added to the infusion. The infusion was then discontinued, and a 30-min recovery period was allowed for insulin levels to return to basal values before the administration of the glucose pulse. Samples for measurement of insulin and glucose were obtained during the subsequent $2 \mathrm{~h}$. The results were compared with a similar study done on a separate day when saline was substituted for the insulin infusion.

To determine the relationship between the fall of plasma glucose during a tolbutamide infusion and the amount of the agent infused, eight normal subjects received different infusion rates of tolbutamide for $1 \mathrm{~h}$ on separate days. Plasma glucose levels were determined during these infusions and compared with a 45-min baseline period.

Eight subjects were infused with tolbutamide at a dose of $7 \mathrm{mg} \cdot \mathrm{m}^{-2} \cdot \mathrm{min}^{-1}$ for $2 \mathrm{~h}$. One hour after starting the tolbutamide infusion, a glucose pulse was given.

In six subjects, a variable rate of glucose infusion was administered during the tolbutamide infusion of $7 \mathrm{mg} \cdot \mathrm{m}^{-2} \cdot \mathrm{min}^{-1}$ in 


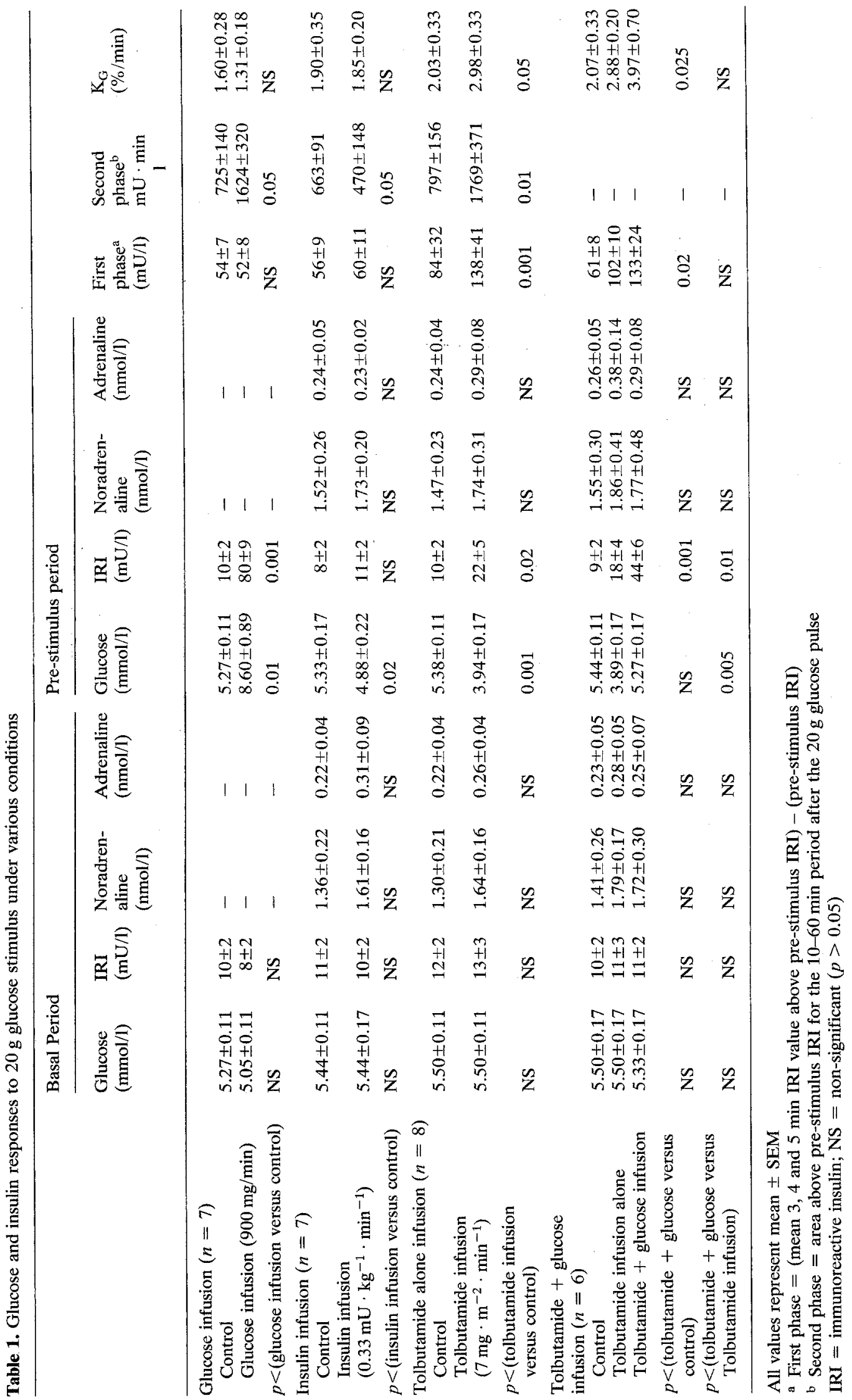




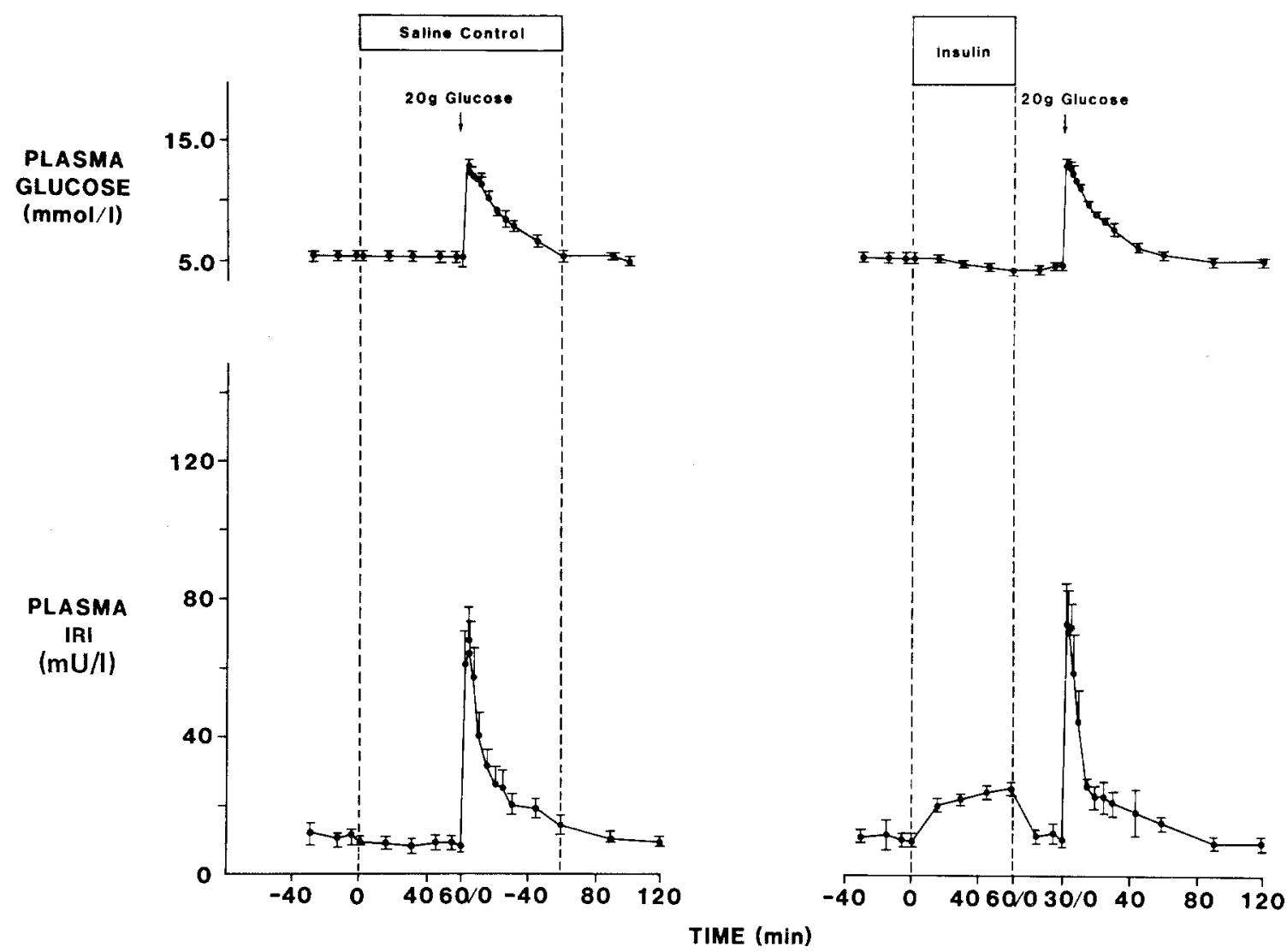

Fig. 2. Effect of a decreased pre-stimulus plasma glucose concentration on insulin release to a $20 \mathrm{~g}$ IV glucose challenge. Pre-stimulus plasma glucose concentration was lowered by insulin $\left(0.33 \mathrm{mU} \cdot \mathrm{kg}^{-1} \cdot \mathrm{min}^{-1}\right)$ in seven subjects. The left panel shows a saline control for the subjects performed on a different day. All values are mean \pm SEM of seven subjects

order to prevent a change in plasma glucose level. The glucose infusion rate was varied every $5 \mathrm{~min}$ based on a bedside measurement of plasma glucose using a Beckman glucose analyzer. The variable glucose infusion was begun at a rate of $200 \mathrm{mg} / \mathrm{min}$, $10 \mathrm{~min}$ after beginning the tolbutamide infusion. The rate at which the glucose was infused was determined as previously described [2]. The glucose infusion rate at the time the glucose pulse was administered was maintained until the study was terminated ( $30 \mathrm{~min}$ after the glucose pulse).

\section{Analytical Methods}

IRI levels were measured by a modification of the double-antibody method of Morgan and Lazarow [4]. Plasma glucose was measured with the autoanalyzer ferricyanide method (Technicon Instruments, Tarrytown, New York). Bedside plasma glucose levels were determined by a glucose oxidase method (Beckman Instruments, Fullerton, California), but these measurements were not used for data analysis. Plasma noradrenaline and adrenaline levels were measured by a single isotope enzymatic assay [5]. The sensitivity of plasma catecholamine assay is $0.11 \mathrm{nmol} / 1$ and coefficient of variation is $12 \%$ for both noradrenaline and adrenaline measurements. Serum tolbutamide concentrations were determined $1 \mathrm{~h}$ after the initiation of the tolbutamide infusion in all subjects. These measurements were performed by the Upjohn Company by a gas-liquid chromatographic method [6]. The sensitivity of the tolbutamide assay is $3.70 \mu \mathrm{mol} / 1$ and the coefficient of variation is $6.4 \%$. Statistical analyses included paired Student's t-test and co-variance analysis with regression.

\section{Results}

\section{The Relationship Between Pre-stimulus Glucose Level and Insulin Responses to IV Glucose}

As shown in Figure 1, during the first $5 \mathrm{~h}$ of the glucose infusion there was a rise in glucose levels from basal glucose, reaching a zenith at $90 \mathrm{~min}(\Delta$ glucose: $+9.05 \pm 1.94 \mathrm{mmol} / \mathrm{l}, n=7, p<0.005$ ). This was followed by a decline to a plateau at $225 \mathrm{~min}$ which was still elevated above the basal level ( $\Delta$ glucose: $+3.61 \pm 1.44 \mathrm{mmol} / 1, n=7, p<0.05$; Table 1 ). This new steady-state glucose level was maintained during the subsequent $135 \mathrm{~min}$ until the time of the glucose pulse. Insulin levels reached a plateau by $120 \mathrm{~min}$ after the basal period ( $\Delta$ IRI at $120 \mathrm{~min}$ : $+84 \pm 5 \mathrm{mU} / \mathrm{l}, n=7, p<0.001)$ and remained at this level until the glucose pulse. After $6 \mathrm{~h}$, there was a significant difference in steady-state insulin ( $\Delta$ IRI: $+70 \pm 7 \mathrm{mU} / 1, n=7, p<0.001)$ and glucose levels $(\Delta$ glucose: $+3.33 \pm 0.89 \mathrm{mmol} / 1, n=7, p<0.01$ ) when compared with the control studies performed on a separate day (Table 1). First phase insulin responses to the $20 \mathrm{~g}$ IV glucose challenge were not 
FIRST PHASE

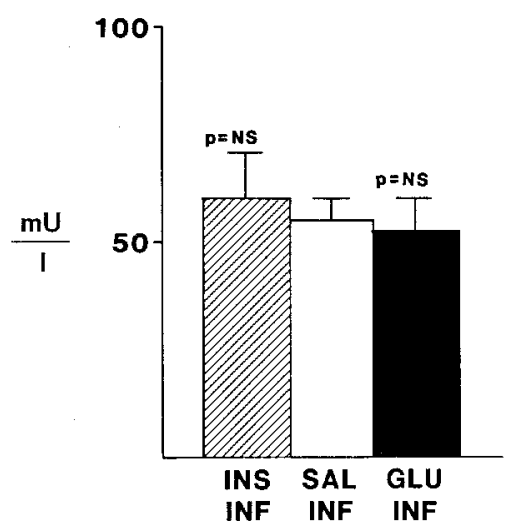

significantly different compared to control studies $(\Delta$ first phase: $-2 \pm 8 \mathrm{mU} / 1, p=\mathrm{NS}$; Fig. 3). However, second phase was increased during this study $(\Delta \mathrm{sec}-$ ond phase: $+889 \pm 333 \mathrm{mU} \cdot \min ^{-1} 1^{-1}, p<0.05$; Fig. 3). Glucose disappearance rate was not changed when compared to the control studies $\left(\Delta \mathrm{K}_{\mathrm{G}}:+0.29\right.$ $\pm 0.27, p=$ NS; Table 1 )

When plasma glucose levels were decreased by insulin infusion (Fig. 2), there was a significant decrease in the second phase insulin response to the $20 \mathrm{~g}$ IV glucose stimulus when compared with the response of the same subjects on a control day $(\Delta$ second phase: $-193 \pm 84 \mathrm{mU} \min ^{-1} 1^{-1}, n=7, p<$ 0.05 ; Fig. 3). However, there was no change in the first phase response ( $\Delta$ first phase: $-5 \pm 9 \mathrm{mU} / \mathrm{l}$, $n=7, p=$ NS; Fig. 3). When compared with the control studies carried out on a separate day, there was a significant decrease in pre-stimulus glucose $(\Delta$ glucose: $-0.44 \pm 0.11 \mathrm{mmol} / \mathrm{l}, n=7, p<0.02$ ) but no significant difference in pre-stimulus insulin $(\Delta$ IRI: $+3 \pm 1 \mathrm{mU} / 1, n=7, p=\mathrm{NS}$ ). Glucose disappearance rate after the glucose pulse was not significantly affected by the insulin infusion $\left(\Delta \mathrm{K}_{\mathrm{G}}:-0.05\right.$ $\pm 0.24, n=7, p=\mathrm{NS}$ ). During and after the insulin infusion, there were no increases in plasma catecholamines compared with the basal period.

Relationship Between Change of Pre-stimulus Glucose Level and Second Phase Insulin Response to IV Glucose: There was a significant linear correlation (Fig. 4) between the change of pre-stimulus glucose from the saline control and the change in second phase insulin secretion from control during either an insulin or glucose infusion $(r=0.65, n=14, p<$ 0.02 ).

\section{Effect of Tolbutamide Studies}

Figure 5 depicts the relationship between the dose of tolbutamide infused and the decrease of plasma glu-
SECOND PHASE

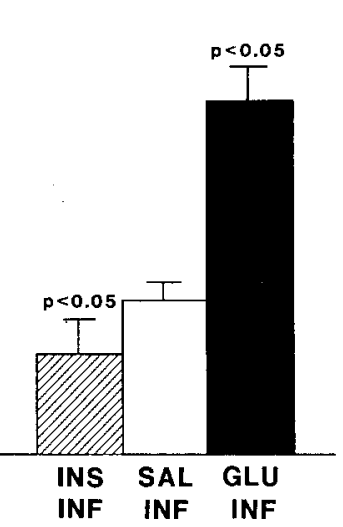

Fig. 3. A summary of the effects of the varying pre-stimulus plasma glucose level on insulin responses to IV glucose. First phase is calculated by the mean change in the 3-5 min insulin value above the pre-stimulus value. Second phase is calculated as the $10-60 \mathrm{~min}$ insulin area above the pre-stimulus value. All values are mean \pm SEM. INS INF $=$ insulin infusion protocol; $\square \mathrm{SAL}$ INF $=$ saline infusion controls; $\square$ GLU INF $=$ glucose infusion protocol

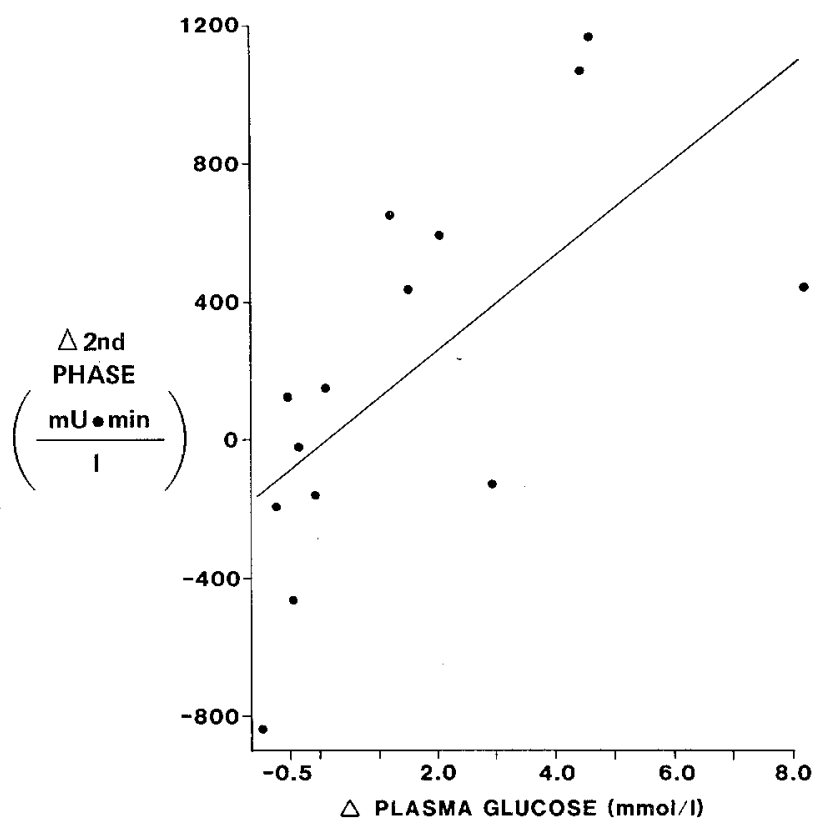

Fig. 4. Relationship of the change in plasma glucose concentration to the change of second phase insulin release in normal man. The change in plasma glucose concentration was calculated as the prestimulus plasma glucose level during either the insulin infusion or glucose infusion protocol minus the pre-stimulus plasma glucose during saline control day. The change of the second phase insulin response was calculated in a similar manner. Second phase $=$ 10-60 min IRI area after glucose pulse. There was a significant linear relationship $(y=8.03 \mathrm{x}-2.15, r=0.65, p<0.02)$

cose level from basal glucose levels 60 min after the start of the infusion in eight normal subjects. A dose of $7 \mathrm{mg} \cdot \mathrm{m}^{-2} \cdot \mathrm{min}^{-1}$ was chosen for the subsequent tolbutamide infusion studies because it caused a modest decline in plasma glucose levels ( $\Delta$ glucose: $-1.61 \pm 0.17 \mathrm{mmol} / 1, n=8, p<0.001$ ) without an increase in plasma catecholamines $(\Delta$ noradrenaline: $+0.09 \pm 0.24 \mathrm{nmol} / 1, n=8, p=\mathrm{NS} ; \Delta$ adrenaline: $+0.09 \pm 0.10 \mathrm{nmol} / 1, n=8, p=\mathrm{NS})$. 


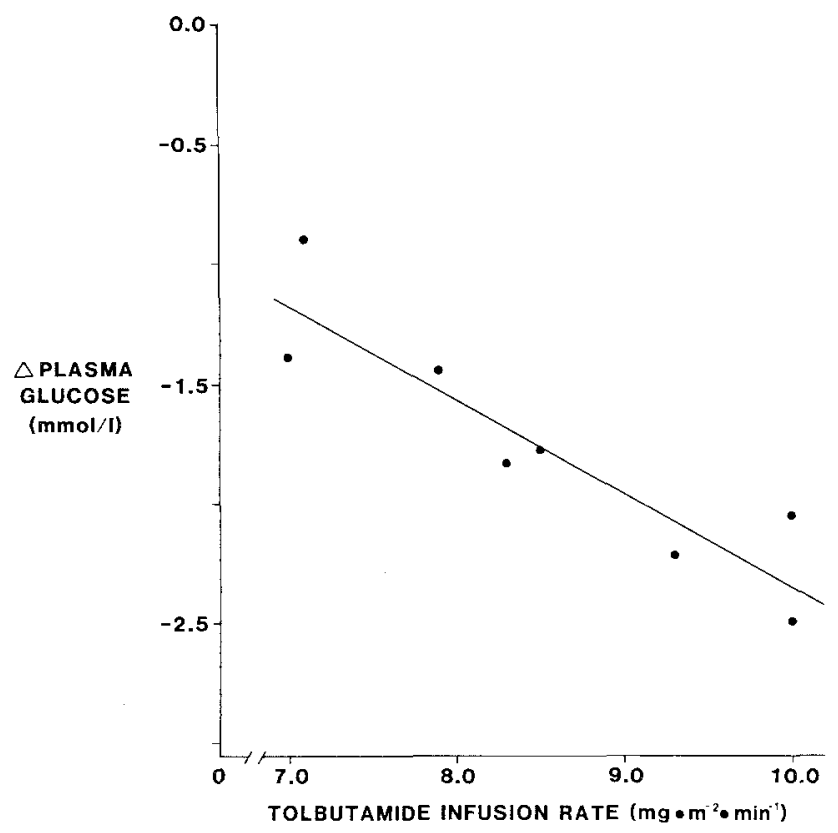

Fig. 5. The relationship between infusion rates of tolbutamide and changes of plasma glucose from basal levels. The change in plasma glucose was determined by subtracting the basal glucose level from that after a $60-\mathrm{min}$ infusion of tolbutamide. There was a significant linear relationship $(y=7.15 \mathrm{x}+29.00, r=0.93, p<0.001)$

A 20-g glucose pulse was given $1 \mathrm{~h}$ after the initiation of a $7 \mathrm{mg} \cdot \mathrm{m}^{-2} \cdot \mathrm{min}^{-1}$ tolbutamide infusion in eight subjects (Fig. 6). A presistent increase in plasma insulin from basal levels was achieved by $30 \mathrm{~min}$ ( $\Delta \mathrm{IRI}$ at $30 \mathrm{~min}:+13 \pm 4 \mathrm{mU} / 1, p<0.01$ ). This was associated with a significant decrease in glucose levels during the first hour of the tolbutamide infusion ( $\Delta$ glucose: $-1.67 \pm 0.17 \mathrm{mmol} / 1, p<$ 0.001 ). When compared to saline control studies (Table 1), there was a significant increase in both the first phase ( $\Delta$ 1st phase: $+54 \pm 13 \mathrm{mU} / \mathrm{l}, p<0.001)$ and second phase $(\Delta$ 2nd phase: $+972 \pm$ $\left.256 \mathrm{mU} \cdot \min ^{-1} \cdot \mathrm{l}^{-1}, p<0.01\right)$ responses to IV glucose. In addition, an increase in $\mathrm{K}_{\mathrm{G}}$ was observed $(\Delta$ $\mathrm{K}_{\mathrm{G}}:+0.95 \pm 0.38, p<0.05$ ). Table 1 demonstrates that there was no elevation of plasma catecholamines from basal levels ( $\Delta$ noradrenaline: $+0.11 \pm$ $0.25 \mathrm{nmol} / 1, p=\mathrm{NS} ; \Delta$ adrenaline: $+0.09 \pm$ $0.09 \mathrm{nmol} / 1, p=\mathrm{NS}$ ) during this modest fall of plasma glucose.

When the fall of plasma glucose during tolbutamide was prevented by a concomitant variable rate glucose infusion, there was no significant change in the first phase insulin response to glucose or the $\mathrm{K}_{\mathrm{G}}$ when compared to the study of tolbutamide alone $\left(+31 \pm 16 \mathrm{mU} / 1, n=6, p=\mathrm{NS} ; \Delta \mathrm{K}_{\mathrm{G}}:+1.08 \pm\right.$ $0.70, n=6, p=$ NS; Table 1$)$. The mean increments observed were all due to one subject who had a marked increase in first phase response to glucose.
However, there was little or no change in the first phase response in the other five subjects. Serum tolbutamide levels were comparable in these studies to those performed without the glucose infusion (tolbutamide infusion alone: $292.58 \pm 31.44 \mu \mathrm{mol} / \mathrm{l}$, $n=6$; tolbutamide plus glucose infusion: $291.10 \pm$ $11.10 \mu \mathrm{mol} / 1, n=6, p=\mathrm{NS}$ ).

When the tolbutamide plus glucose infusion protocol was compared to saline control studies, both first phase ( $\Delta$ first phase: $+72 \pm 20 \mathrm{mU} / 1, p<0.02$ ) and $\mathrm{K}_{\mathrm{G}}\left(\Delta \mathrm{K}_{\mathrm{G}}:+1.90 \pm 0.59, p<0.025\right)$ were increased. When this study was allowed to proceed for $60 \mathrm{~min}$ rather than $30 \mathrm{~min}$, there was such a marked increase in insulin levels that glucose levels fell below $1.67 \mathrm{mmol} / 1$. Second phase insulin release could not be evaluated with this protocol because of the counter regulatory adrenergic responses that occurred.

\section{Discussion}

We have found that the first phase insulin response to a $20 \mathrm{~g}$ glucose challenge is not dependent upon the pre-stimulus glucose level. However, the second phase insulin response is dependent upon the level of glucose before the challenge, in that the higher the pre-stimulus glucose level the greater the second phase response and the lower the pre-stimulus glucose the smaller the second phase. This is consistent with a previous study [7], in which the first phase response to a $5 \mathrm{~g}$ glucose pulse was unchanged during a $20 \mathrm{~h}$ glucose infusion. In apparent contrast, some studies found a decrease in first phase insulin response during a short glucose infusion [7] or in first phase after stopping a glucose infusion [8-10]. The differences between these studies and our study is the lack of a steady-state in the previous studies. It appears that first phase insulin secretion is prestimulus glucose level independent only when a steady-state is achieved.

In contrast, we have found that second phase insulin response to a 20 -g glucose challenge is prestimulus glucose level dependent. Thus, the change of second phase responses to varying pre-stimulus glucose are similar to the changes seen with nonglucose stimuli $[1,2]$. Therefore, any evaluation in second phase response to glucose would necessitate consideration of the pre-stimulus glucose level.

The infusion of tolbutamide was associated with an increase of both first and second phase insulin responses to a $20 \mathrm{~g}$ glucose pulse in normal subjects. These effects occurred in spite of a decrease in prestimulus glucose level. When the plasma glucose level was held constant during the tolbutamide infusion by a variable glucose infusion, the first phase insulin 


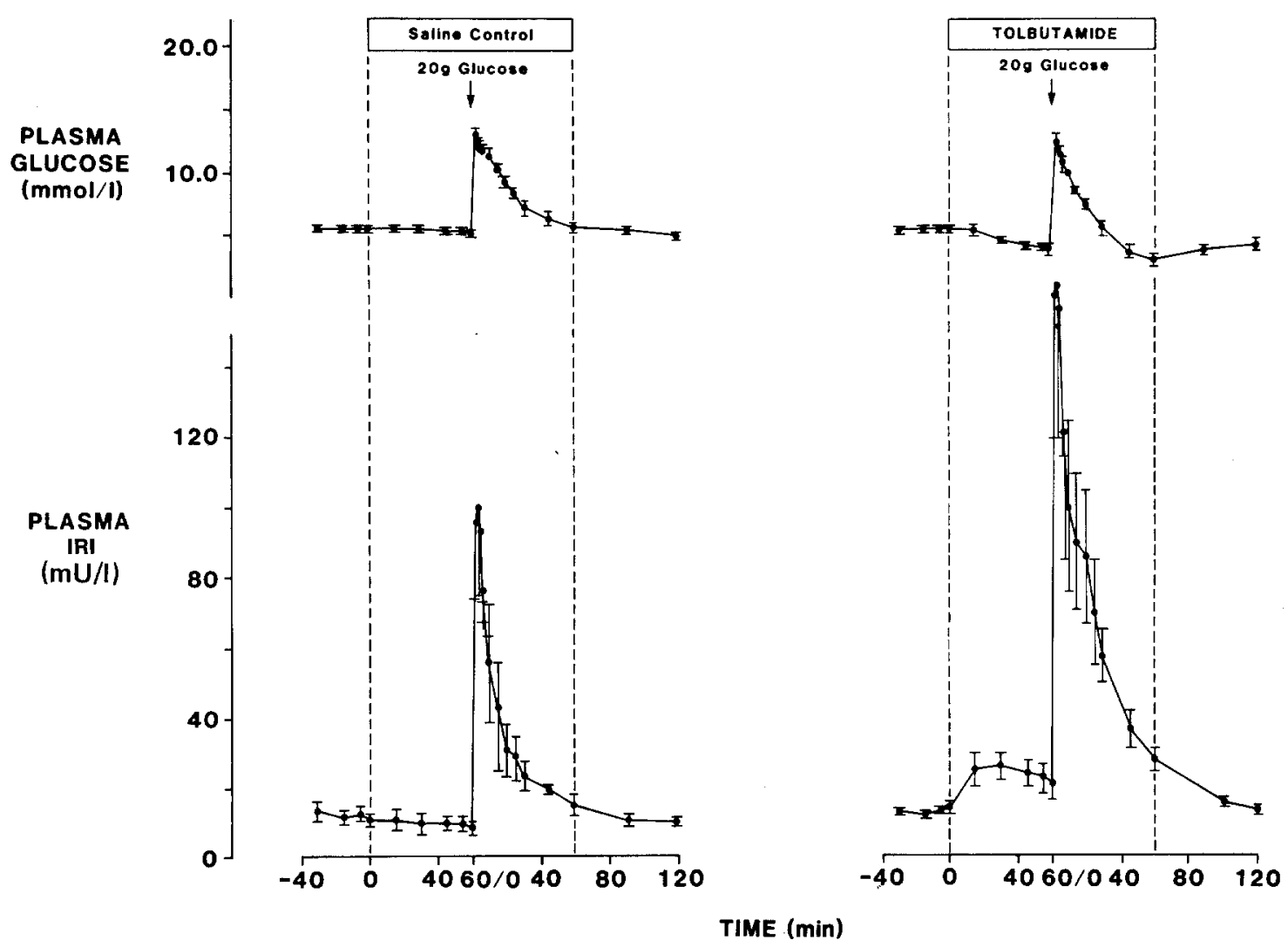

Fig. 6. The effect of a tolbutamide infusion $\left(7 \mathrm{mg} \cdot \mathrm{m}^{-2} \cdot \mathrm{min}^{-1}\right)$ on the insulin response to a 20 -g glucose induced insulin secretion. The control (saline) day is included in the left panel for comparison. All values represent a mean \pm SEM of eight normal subjects

response was the same as that during tolbutamide alone (Table 1). Thus, enhancement of first phase insulin secretion during tolbutamide is due to the drug and is not related to the decrease in glucose level. This lack of effect of pre-stimulus glucose level on first phase insulin secretion during a tolbutamide infusion is consistent with our findings that first phase insulin secretion is not dependent upon the prestimulus plasma glucose levels in the absence of tolbutamide.

The second phase insulin response was also increased by tolbutamide in spite of the decrease in plasma glucose level during the drug infusion (Fig. 6). During the tolbutamide plus variable glucose infusion, there was such a greatly increased insulin response during the initial portion of the second phase time period that hypoglycaemic glucose levels were reached and a counter-regulatory adrenergic response occurred in the latter portion of the second phase time period. Thus, the studies were terminated by stopping the infusions and giving subjects additional glucose before the entire second phase period had been completed. We would speculate that if these subjects had not become hypoglycaemic and the second phase could have been completed, there would have been an even larger increase in second phase. This would have been consistent with our previous findings of glucose level dependency of second phase insulin responses.

The physiological significance of the change in first phase responses in these studies is indicated by $\mathrm{K}_{\mathrm{G}}$. When the first phase was augmented (the tolbutamide alone and the tolbutamide plus glucose protocols), $\mathrm{K}_{\mathrm{G}}$ was increased. In contrast, $\mathrm{K}_{\mathrm{G}}$ did not change in studies in which first phase was not changed (insulin and glucose infusions). These results are consistent with the previously observed relationship of $K_{G}$ to first phase response [11].

These studies of the control of first and second phase insulin secretion by pre-stimulus glucose level may help clarify some questions raised by studies of the chronic effects of sulphonylurea therapy. Hecht et al. [12] observed an increase in first phase insulin secretion to glucose challenge during the course of treatment of diabetics with chlorpropamide. However, second phase insulin secretion was not statistically different from untreated levels. These changes were consistent after one week, one month, and three months of therapy. However, the fasting glucose levels were already decreased at one week and were essentially unchanged thereafter. Our data suggest that this unchanged second phase response in the 
presence of a lower pre-stimulus glucose is still compatible with an islet potentiating action of the drug. This concept was also suggested by Johansen and Ørskov [13] when they observed a decrease in urinary insulin excretion 2-3 days after stopping maintenance sulphonylurea therapy implying that some chronic insulinotrophic effect had been removed.

In summary, the present study shows that second phase, but not first phase, insulin secretion during an IV glucose tolerance test is dependent on the prestimulus glucose level in normal man and that tolbutamide increases both first and second phase insulin secretion. These findings may explain some of the apparent discrepancies concerning the ability of the sulphonylureas to influence insulin secretion in diabetic patients. It seems likely that sulphonylurea therapy always enhances insulin secretion but that the effect on second phase insulin secretion may be obscured by a fall in plasma glucose. Since there is a slow fall of plasma glucose after treatment with an oral agent, we hypothesize that studies performed during the early phase of treatment or which specifically test first phase insulin release to glucose will show an increase of insulin release [12, 14]. In contrast, studies which are performed later after a new lower steady-state glucose level has been achieved and which examine oral glucose tolerance or second phase insulin secretion, would find no apparent change in insulin secretion [15-19]. We suggest that these apparent discrepancies can be resolved by recognising that the pre-stimulus glucose level is an important modulator of second phase insulin responses to glucose.

Acknowledgments. This investigation was supported in part by a Public Health Service Special Emphasis Research Career Award (AM 00738) from the National Heart, Lung, and Blood Institute, the National Institute of Arthritis, Metabolism, and Digestive Diseases (AM 12829, AM 20754, and AM 17047), and by the Veterans Administration.

The authors wish to thank Mr. Howard Beiter, Ms. Barbara O'Neill, Ms. Karen Smith, and Ms. Connie Holmes for their technical assistance, and Mrs. Pat Jenkins, Ms. Anne Bartlett, and Mrs. Maxine Cormier for their secretarial assistance. The authors would also like to thank the Upjohn Company for measurement of serum tolbutamide concentration, and Mr.J.T. Keene and Mr. L. Helser of the Upjohn Company for their assistance.

\section{References}

1. Pfeifer MA, Halter JB, Graf RJ, Porte D Jr (1980) Potentiation of insulin secretion to non-glucose stimuli in normal man by tolbutamide. Diabetes 29: 335-340

2. Halter JB, Graf RJ, Porte D Jr (1979) Potentiation of insulin secretion responses by plasma glucose levels in man: Evidence that hyperglycemia in diabetes compensates for impaired glucose potentiation. J Clin Endocrinol Metab 48: 946-954
3. Lerner RL, Porte D Jr (1971) Relationships between intravenous glucose loads, insulin responses and glucose disappearance rate. J Clin Endocrinol 33: 409-417

4. Morgan CR, Lazarow A (1963) Immunoassay of insulin: Two antibody system. Diabetes 12: 115-126

5. Evans MI, Halter JB, Porte D Jr (1978) Comparison of double- and single-isotope enzymatic derivative methods for measuring catecholamines in human plasma. Clin Chem 24: $567-570$

6. Matin SB, Rowland M (1973) Determination of tolbutamide and chlorpropamide in biological fluids. J Pharm Pharmacol 25: 186-188

7. Porte D Jr, Pupo AA (1969) Insulin responses to glucose: evidence for a two pool system in man. J Clin Invest 48: 2309-2319

8. Cerasi E (1975) Potentiation of insulin release by glucose in man. I. Quantitative analysis of the enhancement of glucoseinduced insulin secretion by pretreatment with glucose in normal subjects. Acta Endocrinol 79: 483-501

9. Cerasi E (1975) Potentiation of insulin release by glucose in man. III. Normal recognition of glucose as a potentiator in subjects with low insulin response and in mild diabetes. Acta Endocrinol 79: 511-534

10. Cerasi E (1975) Insulin secretion: mechanism of the stimulation by glucose. Q Rev Biophys 8: 1-41

11. Brunzell JD, Robertson RP, Lerner RL, Hazzard WR, Ensinck JW, Bierman EL, Porte D Jr (1976) Relationships between fasting plasma glucose levels and insulin secretion during intravenous glucose tolerance tests. J Clin Endocrinol Metab 42: 222-229

12. Hecht A, Gershberg H, Hulse M (1973) Effect of chlorpropamide treatment on insulin secretion in diabetics: its relationship to the hypoglycemic effect. Metabolism 22: 723-733

13. Johansen K, Ørskov H (1972) The stimulatory effect on insulin secretion in long term tolbutamide treatment. Immunological determinations of urinary and serum insulin. Acta Endocrinol 71: 709-715

14. Turner RC, Holman RR (1978) Beta cell function during insulin or chlorpropamide treatment of maturity-onset diabetes mellitus. Diabetes 27: 241-246

15. Seltzer HS, Allen EW, Brennan MT (1965) Failure of prolonged sulfonylurea administration to enhance insulinogenic response to glycemic stimulus. Diabetes 14: 392-395

16. Reaven G, Dary J (1967) Effect of chlorpropamide on serum glucose and immunoreactive insulin concentrations in patients with maturity-onset diabetes mellitus. Diabetes 16: 487-492

17. Chu P-C, Conway MJ, Krouse HA, Goodner CJ (1968) The pattern of response of plasma insulin and glucose to meals and fasting during chlorpropamide therapy. Ann Intern Med 68: 757-769

18. Shenfield GM, Logan A, Shirlíng D, Baird J (1977) Plasma insulin and glucose levels in maturity onset diabetics treated with chlorpropamide. Diabetologia 13: 367-371

19. Duckworth WC, Soloman SS, Kitabchi AE (1972) Effect of chronic sulfonylurea therapy on plasma insulin and proinsulin levels. J Clin Endocrinol Metab 35: 585-591

Received: 12 June 1980

and in revised form: 27 April 1981

Michael A. Pfeifer, M. D.

Medical Research Service (151)

VA Medical Center

4435 Beacon Avenue South

Seattle, Washington 98108 , USA 